\title{
Design of the control circuit of automatic dryer
}

\author{
Biqing $\mathrm{Li}^{1 \text {, a }}$, Zhao Li ${ }^{2,}$ b, ${ }^{*}$, Hongyan Zhang ${ }^{1, \text { a }}$ \\ ${ }^{1}$ School of Information and Communication Engineering, Hezhou University, Hezhou Guangxi 542899, \\ China; \\ ${ }^{2}$ Management Engineering Department, Guangxi Vocational and Technical College of \\ Communications, Nanning Guangxi 545000, China; \\ ajanliful@163.com, b229292710@qq.com
}

\begin{abstract}
Keywords: the temperature and humidity of the received signal after processing is sent to the display shows the number, when the value reaches the initial settings required the relay to control the motor, closed, the dryer to stop working, the GSM module and the remote user information exchange, automatically send text messages that have been drying clothes. The design of remote control system to overcome the distance to and understanding the working state and the password protection dryer faults, scalability and use value has a good.
\end{abstract}

Abstract. GSM; STC89C52; DHT11; A clothes dryer.

\section{Introduction}

The general type of clothes dryer on the market is divided into drum type and cabinet type at present. Drum type is generally combined with washing machines to use, and mainly spin-drying clothes, and the volume is small; cabinet machine is to use oven to dry clothes with a larger capacity. Compared to the drum dryer, the cabinet type is better than the former, because the cabinet type is drying clothes when the clothes are hung, which largely avoids the folds of the clothes and reduces the subsequent steps to be ironed.

\section{Overall Design}

\subsection{Design Requirements}

Testing clothes humidity, and can automatically shut down after drying clothes;

Text messaging after shutting down.

\subsection{Design Scheme And Theoretical Analysis}

The design uses the STC89C52 as a controller to meet the information storage and analog acquisition, plus GSM for information transfer module users, and sensor module as data collection, forming a minimum system to complete the remote control and other functions. Among them, GSM communication module is responsible for receiving and transmitting information requested by users in these schemes, the relay is responsible for controlling the work of the motor,the temperature and humidity collection is controlled by the temperature and humidity sensor of the control subsystem, and the liquid crystal display module displays the working status of the module and its surroundings real-time data.

\subsection{Performance Introduction of STC89C52 Microcontroller}

There are 8-bit CPU in STC89C52 microcontroller,with Flash memory in which 8K bytes of memory flashing programmable can also be deleted and allows program memory online programming [4], but also for conventional programmer. The versatile combination of programmable flash memory cells in the system can be turned into a highly efficient microcontroller on a single chip, which is a CMOS 8-bit microcontroller with low power, high speed and reliable, strong antistatic interference, powerful and high performance that makes the STC89C52 provides a highly flexible and cost-effective solution for many embedded control applications. 


\begin{tabular}{|c|c|c|c|}
\hline (T2) P1.0 C & 1 & 40 & pvec \\
\hline (T2 EX) P1.1 C & 2 & 39 & PO. (ADO) \\
\hline P1.2 & 3 & 38 & PO.1 (AD1) \\
\hline P1.3 C & 4 & 37 & P0.2 (AD2) \\
\hline P1.4 ᄃ & 5 & 36 & PO.3 (AD3) \\
\hline (MOSI) P1.5 ᄃ & 6 & 35 & P0.4 (AD4) \\
\hline (MISO) P1.6 & 7 & 34 & PO.5 (AD5) \\
\hline (SCK) P1.7 ᄃ & 8 & 33 & PO. 6 (AD6) \\
\hline RST ᄃ & 9 & 32 & P0.7 (AD7) \\
\hline (RXD) P3.0 C & 10 & 31 & 口馬NPP \\
\hline (TXD) P3.1 L & 11 & 30 & ALESPROG \\
\hline 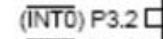 & 12 & 29 & 口 $\overline{\text { PSEN }}$ \\
\hline (INT1) P3.3 C & 13 & 28 & P2.7 (A15) \\
\hline (TO) P3.4 ᄃ & 14 & 27 & P2.6 (A14) \\
\hline (T1) P3.5 प & 15 & 26 & P2.5 (A13) \\
\hline$(\overline{W R})$ P3.6 प & 16 & 25 & P2.4 (A12) \\
\hline ( $\overline{R D})$ P 3.7 C & 17 & 24 & P2.3 (A11) \\
\hline XTAL2 & 18 & 23 & P2.2(A10) \\
\hline XTAL1 드 & 10 & 22 & P2.1 (A9) \\
\hline GND 듬 & 20 & 21 & P2.0(AB) \\
\hline
\end{tabular}

Figure 1 Each Pin Label of STC89C52

The pins RXD and TXD are the inputs and outputs of the high-gain inverting amplifier respectively. The RST pin (Pin19) is used to reset the input. When the crystal oscillator is in operation, the RST pin lasts for 2 machine cycles to reset the microcontroller. The EA / VPP pin accesses the external program memory control signal. In order to execute internal program instructions, the EA should be connected to Vcc. To enable an external program memory read instructions from $0000 \mathrm{H}$ to FFFFH, the EA must be connected to GND. The EA also receives a 12 volt VPP voltage during programming.

\subsection{Reset Circuit}

There are many ways to start the reset circuit. In general, a simple reset circuit only needs a combination of a resistor and a capacitor to form a reset circuit. One is the power reset, which provides a reset signal when the system is powered on, directly to make the microcontroller work, whose start and stop is controlled by the power; and the other is to reset circuit design and switch in the circuit, which is to set foreign key, which is to control the circuit reset through the manual key switch, thereby controlling the microcontroller reset. The design uses the second method, the circuit diagram shown in Figure 4.

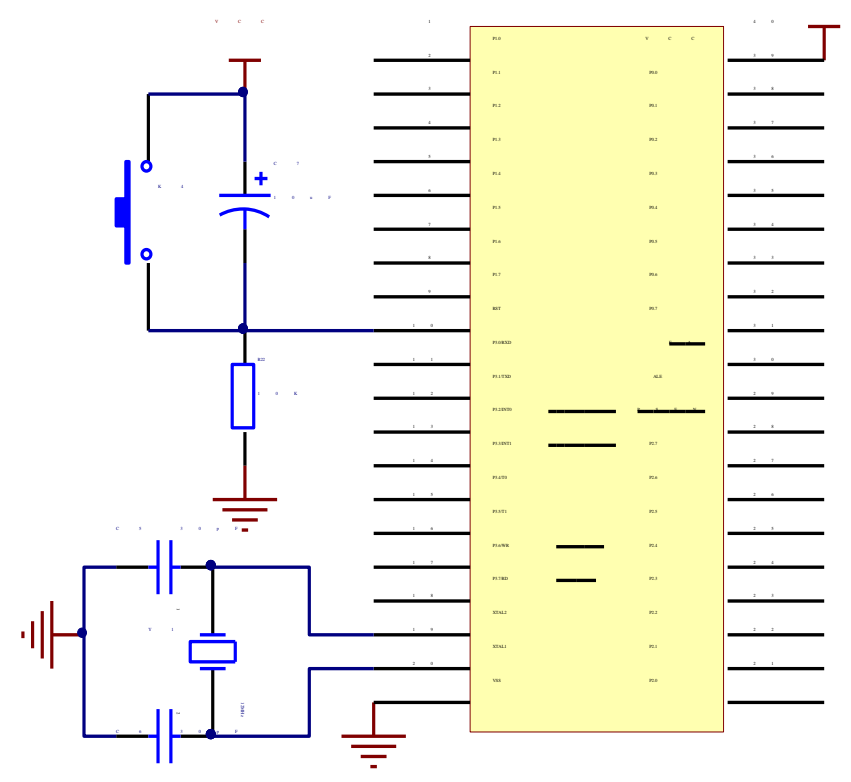

Figure 2 STC89C52 Microcontroller Reset Circuit, Crystal Oscillator Circuit Diagram

The circuit used a mobile GSM technology module, and data transmission distance can be globally communicated after this circuit processing, that is, no matter where you are, you can meet SMS alert 
function of the requirements of our system as long as there is a signal; the serial port was used for the communication between MCU and GSM module, and the default baud rate was 9600 .

\subsection{DHT11 Temperature And Humidity Sensor}

DHT11 digital temperature and humidity, also known as temperature and humidity composite sensor, whose supply voltage of $3 \mathrm{~V} \sim 5.5 \mathrm{~V}$, and it uses a dedicated digital module acquisition technology and temperature and humidity sensing technology, is a composite sensor with calibrated digital signal output, and its calibration coefficients are stored in OTP memory in the form of a program. These calibration coefficients are invoked inside the sensor during signal processing to ensure extremely high product reliability and excellent long-term stability.

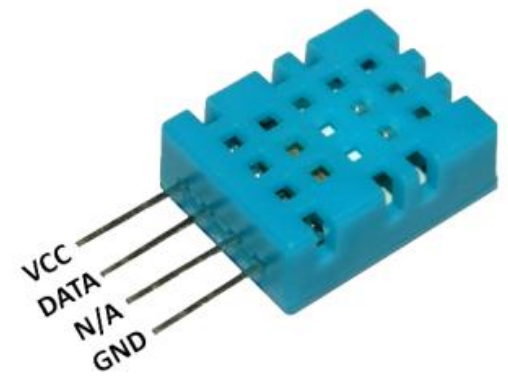

Figure 3 Physical Map of DHT11

\section{Software Design}

\subsection{Program Flow}

Initialization process is divided into modules, and only each module be able to retrieve the work normally can the next module initialize, so that not only increases the readability of the program, but also facilitate the sub-module testing and debugging, shortening the debugging cycle and testing conveniently.

When the normal initialization of each module is completed, the program enters an infinite loop. The contents of the loop body are as follows: First, it starts to judge whether or not the work instruction message of the relevant motor is received. If the ON instruction of turning on the motor is received, the control board sends two corresponding coordinate password to the GSM module, which will work to send the corresponding password to the control panel, which is to determine whether the password is correct or not, if correct, open the motor, otherwise return an error message and give feedback.

\subsection{Serial Port Interrupt to Serve Subroutine}

Interrupt subroutine is an important hub of the reception and transmission of the control data in the design, as shown in Figure 8, the receiving interrupt copies the data to the pre-set data storage area recive_buff, while the storage area determining whether the received data is the new message arrival notification or not, if it is, the next step is to determine the command to put SMS on flagged location 1, otherwise the flagged location 0 and end, so loop the program to determine like this until meet the sub-commands of the various steps of the module. The implementation of whether to read SMS by the way of judging flagged position in the main program, saving the process of program services, and shortening the waste time of reading data due to the lack of SMS.

\section{GSM Module Initialization Subroutine}

In this design, due to the GSM module is the core of the system after the completion of motor work and exchanging with the user data. If the GSM module can not work properly, the motor system of microcontroller can not work properly. Therefore, the initialization of GSM uses the cyclic programming mainly to facilitate the normal operation of each module initialization. Only after each command is normal executed meeting the set requirements can the next executive command be sent.

A part of code as follow: 


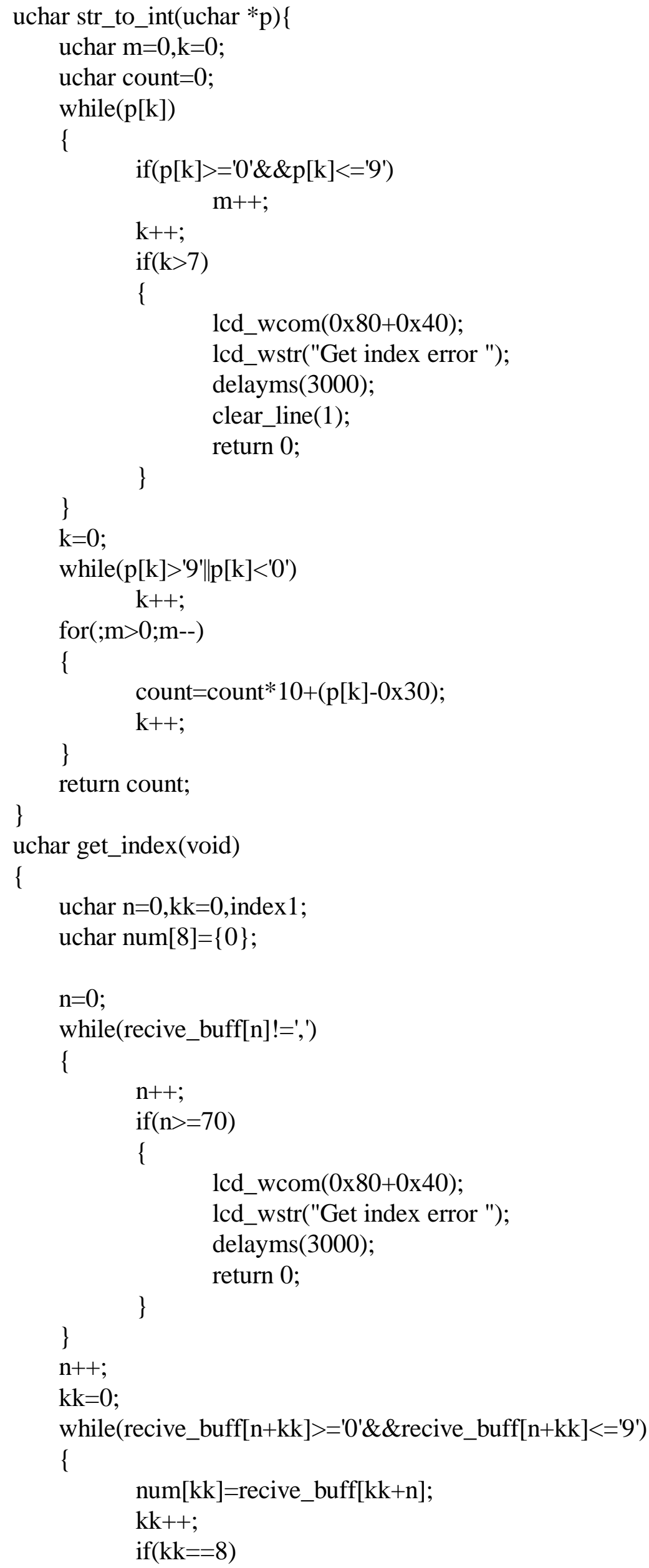




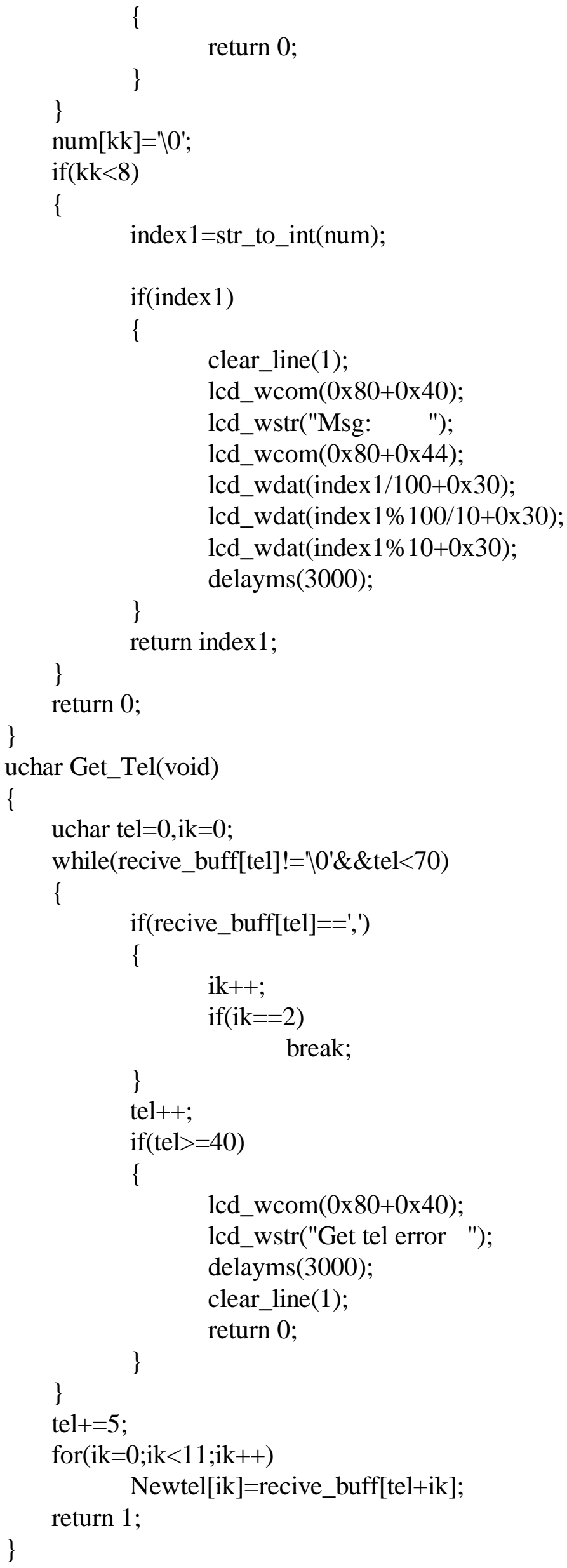




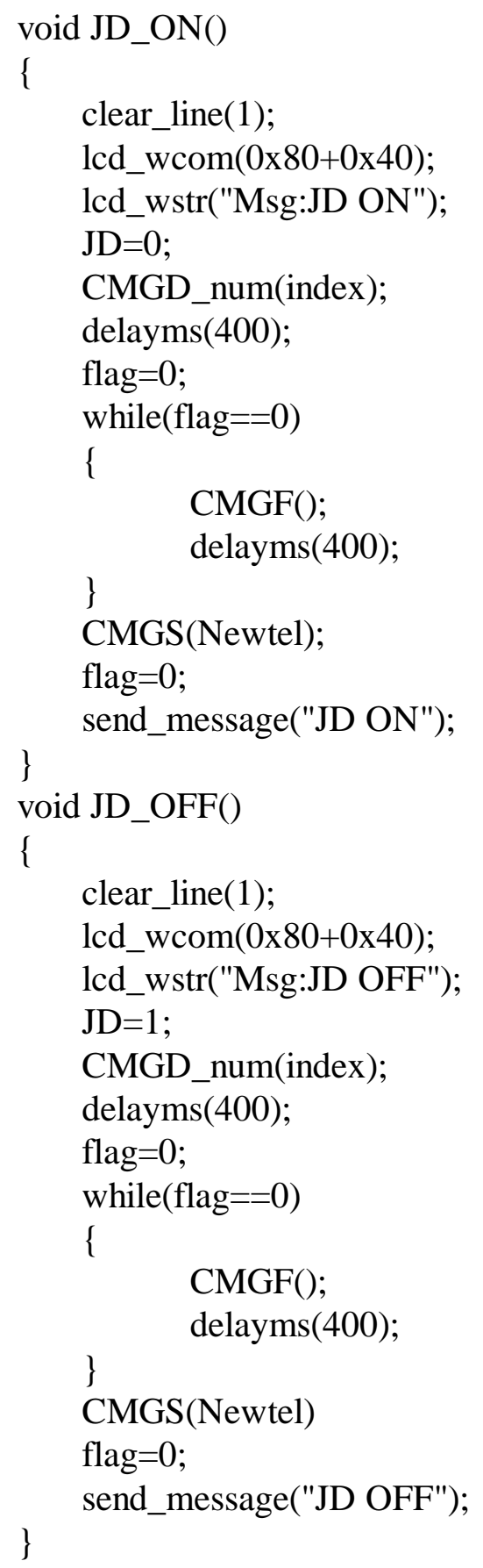

\subsection{Hardware Debugging}

In the process of circuit testing, we mainly use digital multimeter to test whether there exist welding problems in various modules, such as rosin joint and solder skips, and whether the working voltage is normal or not to facilitate repair if there are problems.

Finally is the test of the entire work.Press the button switch after connecting the circuit, and then put a small piece of wet clothes beside, next, the microcontroller chip starts working according to the parameters required which has been set.When humidity and temperature of dryer drying meets the setting value, the relay controls the dryer to turn-off the circuit and the dryer stops working, and the GSM SMS module sends a instruction to the phone to remind the clothes have been dry. 
List of Original And Debugging Tools

\begin{tabular}{|c|c|c|}
\hline Name & Specification / Model & Quantity \\
\hline Microcontroller & STC89C52 & 1 \\
\hline Pedestal of Microcontroller & 40P IC Pedestal & 1 \\
\hline Crystal Oscillator & 11.0592MHz Quartz Crystal & 1 \\
\hline 30pF Capacitor & 30pF Ceramic Capacitor & 2 \\
\hline 10K Pull-up Resistor & 10K Exclusion 9P & 1 \\
\hline LCD1602 Viewing Screen & & 1 \\
\hline $\begin{array}{l}\text { Temperature And Humidity } \\
\text { Sensor }\end{array}$ & DHT11 & 1 \\
\hline GSM Mmodule & SIM900A & 1 \\
\hline 470uF Capacitor & Electrolytic Capacitor & 1 \\
\hline Potentiometer & 10K Potentiometer & 1 \\
\hline Tuch-button & & 4 \\
\hline Battery Compartment & & 1 \\
\hline $\mathrm{CCL}$ & & 1 \\
\hline 40P Block & 100mil Spacing & 1 \\
\hline Power Switch & & 1 \\
\hline LED Light & Light-Emitting Diode & 2 \\
\hline $1 \mathrm{~K}$ Resistor & & 4 \\
\hline Temperature Sensor & DS18b20 & 1 \\
\hline Buzzer & 5V Active Buzzer & \\
\hline PNP Transistor & $\mathrm{S} 8550$ & 2 \\
\hline Relay & SRD-05VDC-SL-C & 1 \\
\hline Switching Diode & $1 \mathrm{~N} 4148$ & 1 \\
\hline USB Power Cable & Male to Male & 1 \\
\hline Digital Multimeter & & 1 \\
\hline GSM Card & & 2 \\
\hline Phone & & 1 \\
\hline
\end{tabular}

\section{Summary}

Through months of continuous learning and practice, my design was finally completed. This work is supported the following fund :

2017 The student work subject program of Hezhou university:"college students' network addiction of the student work service research"(No,hzxysz201707).

2016 The higher education research subject project project of Hezhou university:"between collaborative innovation research of entrepreneurial talent cultivation system".

2016 Guangxi university scientific research project:"Study on image processing based on digital compression sensing theory of intelligent robot"(No,KY2016YB454).

2017 college students' innovative entrepreneurial project:'The agricultural robot autonomous operations research based on machine vision"(No,201711838096) \&\&"Multi-functional autonomous agriculture robot development"(No,201711838121) \&\&"Research and development of navigation system for agricultural robot"(No,201711838008) \&\&"Research and development of data acquisition system and servo control system for mobile platform of agricultural robot" (No,201711838075) \&\&"Research and development of visual navigation system for agricultural robot test platform"(No,201711838076).

2017 Guangxi education science 'ten-three-five' planning project:'Based on zte's ICT education platform of fusion, work-integrated learning education training mode research"(No,2017B107). 


\section{References}

[1] B.Q LI, Y.F LING, H.Y ZHANG, S.Y ZHENG: The Design and Realization of Cherry Tomato Harvesting Robot Based on IOT. International Journal of Online Engineering, 12(12), 23, (2016).

[2] B.Q LI, W.L GUAN, S.Y ZHENG, X.G Yue: OPTIMISATION DESIGN OF CORN PRECISION SEEDER BASED ON MULTI-ROUTE AND MULTI-CHANNEL CONTROL. JOURNAL OF THE BALKAN TRIBOLOGICAL ASSOCIATION, 21(4A), 1215, (2015).

[3]B.Q LI, X.M YANG GUAN, S.Y ZHENG: Internet of Things-based Simulation Study on Lijiang River Water Environment Monitoring. Journal of Coastal Research,79, 1-5, (2017).

[4] B.Q Li, et al, Intelligent Control Management System and Its Application, in: PROCEEDINGS OF THE 2016 INTERNATIONAL CONFERENCE ON ECONOMICS AND MANAGEMENT INNOVATIONS, Wuhan, China, 2016, PP.68-71.

[5] B.Q Li, et al, Design and Implementation of Tanks War Game Based on the Android Platform, in: PROCEEDINGS OF THE 2016 2ND WROKSHOP ON ADVANCED RESEARCH AND TECHNOLOGY IN INDUSTRY APPLICATIONS, Dalian, China, 2016, PP.963-966.

[6] B.Q Li, et al, Design of a Tea Garden Antifreezing Control System, in: PROCEEDINGS OF THE 2016 6TH INTERNATIONAL CONFERENCE ON MACHINERY, MATERIALS, ENVIRONMENT, BIOTECHNOLOGY AND COMPUTER(MMEBC), Tianjin, China, 2016, PP.736-738.

[7] B.Q Li, et al, Design of Electronic Compass, in: PROCEEDINGS OF THE 2016 6TH INTERNATIONAL CONFERENCE ON MACHINERY ,MATERIALS, ENVIRONMENT, BIOTECHNOLOGY AND COMPUTER(MMEBC), Tianjin, China, 2016, PP.1240-1243.

[8] B.Q Li, et al, Research of Automatically Light-Adjusting Lamp, in: PROCEEDINGS OF THE 2016 INTERNATIONAL CONFERENCE ON COMPUTER ENGINEERING, INFORMATION SCIENCE \& APPLICATION TECHNOLOGY (ICCIA 2016), Guilin, China, 2016, PP.249-252.

[9] B.Q Li, et al, The Design and Realization of Fruit Harvesting Robot Based on IOT, in: PROCEEDINGS OF THE 2016 INTERNATIONAL CONFERENCE ON COMPUTER ENGINEERING,INFORMATION SCIENCE \& APPLICATION TECHNOLOGY (ICCIA 2016), Guilin, China, 2016, PP.261-264.

[10] B.Q Li, et al, A New Type of Automatic Opening and Closing Light-Operated Curtain, in: PROCEEDINGS OF THE 2016 INTERNATIONAL CONFERENCE ON MECHATRONICS ENGINEERING AND INFORMATION TECHNOLOGY(ICMEIT), Xian, China, 2016, PP.66-69.

[11] B.Q Li, et al, Design of the Intelligent Air Humidifier, in: PROCEEDINGS OF THE 2016 INTERNATIONAL CONFERENCE ON MECHATRONICS ENGINEERING AND INFORMATION TECHNOLOGY (ICMEIT), Xian, China, 2016, PP.201-203.

[12] B.Q Li, et al, The Design Implementation of the APP of Experiencing Guangxi Folk Custom, in: PROCEEDINGS OF THE 2016 INTERNATIONAL CONFERENCE ON ECONOMICS AND MANAGEMENT INNOVATIONS, Wuhan, China, 2016, PP.47-50.

[13] S.Y Zheng, et al, Digital Display Design of Ethnic Clothing of Nanling, in: PROCEEDINGS OF THE 4TH INTERNATIONAL CONFERENCE ON MECHATRONICS, MATERIALS. CHEMISTRY AND COMPUTER ENGINEERING 2015(ICMMCCE 2015), Xian, China, 2015, PP.2805-2808.

[14] S.Y Zheng, et al, Design and Implementation of Supermarket Personnel Management System Based On Java, in: PROCEEDINGS OF THE 2015 INTERNATIONAL CONFERENCE ON EDEDUCATION,MANAGEMENT AND COMPUTING TECHNOLOGY(ICEMCT-16), Hangzhou, China, 2016, PP.957-960.

[16] S.Y Zheng, et al, Brief analysis on“HeYuanTong”Campus Mobile Phone APP Design, in: PROCEEDINGS OF THE 2015 5TH INTERNATIONAL CONFERENCE ON COMPUTER SCIENCES AND AUTOMATION ENGINEERING, Sanya, China, 2015, PP.151-154. 
[17]S.Y Zheng, et al, Social Work in Teen Addiction Correction Services Research Under the New Situation, in: PROCEEDINGS OF THE 2015 4TH NATIONAL CONFERENCE ON ELECTRICAL, ELECTRONICS AND COMPUTER ENGINEEERING(NCEECE 2015), Xian, China, 2015, PP.252-255.

[18] B.Q Li, et al, The Design of Remote Temperature Monitoring System, in:International Conference on Green Energy and Sustainable Development, MAY 27-28, 2017, PP.20-22.

[19] B.Q Li, et al, Design of Portable Valuables Touch Alarm Circuit,in:International Conference on Advances in Materials, Machinery, Electronics ,2017, PP.27-32.

[20] B.Q Li, et al, Design and Implementation of a Simple Acousto Optic Dual Control Circuit,in:5th International Conference on Computer-Aided Design, Manufacturing, Modeling and Simulation,2017, PP.78-80.

[21] B.Q Li, et al, Design of electronic lock based on single-chip microcomputer,in:4th International Conference on Electrical and Electronics Engineering and Computer Science ,2017, PP.55-60.

[22] B.Q Li, et al, The Design of Chicken House Electronic Intelligent Lighting Apparatus, in: International Conference on Mechanical, Electronic, Control and Automation Engineering,2017, PP.15-20.

[23] B.Q Li, et al, Office Automation Sub-Summary of the Work and the Project Management System, in: International Conference on Mechanical, Electronic, Control and Automation Engineering, 2017, PP.46-48.

[24] B.Q Li, et al, The Design of Intelligent Heat Dissipator Control Circuit,in:PROCEEDINGS OF THE 2017 2ND INTERNATIONAL CONFERENCE ON MATERIALS SCIENCE, MACHINERY AND ENERGY ENGINEERING,2017, PP.22-25.

[25] B.Q Li, et al, The Design of IPv6's Transitional Scheme in University, in:International Conference on Materials Science, Energy Technology, Power Engineering (MEP) ,2017, PP.91-93.

[26] B.Q Li, et al, The Personal Receiving Document Management and the Realization of Email Function in OAS,in:International Conference on Materials Science, Energy Technology, Power Engineering (MEP) ,2017, PP.121-123.

[27] S.Y Zheng, et al, Design and Implementation of an Audio Indicator,in: 5th International Conference on Computer-Aided Design, Manufacturing, Modeling and Simulation,2017, PP.21-23.

[28] S.Y Zheng, et al, Implementation and Application of ACL in Campus Network, in: International Conference on Advances in Materials, Machinery, Electronics ,2017, PP.151-153.

[29] S. Y Zheng, et al, The Design of Liquid Drip Speed Monitoring Device System Based on MCU,in: International Conference on Green Energy and Sustainable Development, MAY 27-28, 2017, PP.51-53.

[30] S.Y Zheng, et al, The Design of Hearing and hypnosis all-in-one Machine, in:International Conference on Mechanical, Electronic, Control and Automation Engineering,2017, PP.66-68.

[31] S.Y Zheng, et al, Campus Network Security Defense Strategy,in:International Conference on Mechanical, Electronic, Control and Automation Engineering,2017, PP.30-33.

[32] S.Y Zheng, et al, Design and implementation of multifunctional charger,in:International Conference on Materials Science, Energy Technology, Power Engineering (MEP) ,2017, PP.71-73. 